\title{
Fetal Alcohol Spectrum Disorders: Survey of Healthcare Providers after Continuing Education
}

\author{
Shirley F. Evans ${ }^{1, *}$, Leigh E. Tenkku ${ }^{2}$, Tay Kennedy ${ }^{1}$, Roger Zoorob ${ }^{3}$ and P. Kevin Rudeen ${ }^{4}$ \\ ${ }^{1}$ Department of Nutritional Sciences, Oklahoma State University, Stillwater, OK, USA \\ ${ }^{2}$ University of Missouri, Columbia, MO, USA \\ ${ }^{3}$ Department of Family and Community Medicine, Baylor College of Medicine, Houston, TX, USA \\ ${ }^{4}$ College of Allied Health, University of Oklahoma Health Sciences Center in Oklahoma City, OK, USA
}

\begin{abstract}
Fetal alcohol spectrum disorders (FASD) occur as a result of prenatal alcohol exposure and are commonly associated with intellectual disability. Maternal alcohol consumption affects fetal development resulting in numerous lifelong physical, mental, and neurobehavioral abnormalities. To promote prevention of prenatal alcohol exposure and intervention to mitigate alcohol's postnatal effects, the Centers for Disease Control and Prevention (CDC) provides continuing education to healthcare providers through their FASD Regional Training Centers (RTCs). An online survey evaluated healthcare providers' perceived competency after training. Cover letters with the survey link were electronically mailed to healthcare providers, who received training between 2002 and 2009 from the Midwest and Southeast RTCs. Eighty-two providers who treated women or children responded to the survey (7.5\% response rate). Approximately $86 \%$ of providers who treated women have identified women 'at risk' for alcohol abuse with $90 \%$ indicating they would refer to Substance Abuse or Mental Health Services. However, over $25 \%$ perceived lack of training and limited time as barriers in treating women of childbearing age for at-risk drinking. Over $90 \%$ of providers who treated children reported feeling competent in recognizing FAS and other alcohol-related effects. Yet, only $23 \%$ of providers for children reported using FASD diagnostic schema and were more apt to use growth charts $(70 \%)$ rather than lip philtrum guides $(58 \%)$ or palpebral fissure length measurements $(50 \%)$, tools typically used in FAS determination. These results suggest a need for training to focus on methodology that assists providers to easily incorporate screening, diagnostic, and treatment procedures into their daily practice.
\end{abstract}

Keywords: Fetal alcohol syndrome, prenatal alcohol exposure, intellectual disability, healthcare training, practice behaviors.

\section{INTRODUCTION}

Maternal alcohol consumption during pregnancy can affect the development of the fetus, resulting in various disorders with lifelong physical, mental, and neurobehavioral abnormalities that range from minor to severe [1]. While not a clinical term, fetal alcohol spectrum disorders (FASD) represent all disabilities in children following exposure to prenatal alcohol [2, 3]. In the Diagnostic and Statistical Manual of Mental Disorders, Fifth Edition, FASD is classified as a Neurodevelopmental Disorder associated with Prenatal Alcohol Exposure (ND-PAE) [4, 5]. The reduction in the occurrence of fetal alcohol syndrome, one of the leading preventable causes of intellectual disability and the most severe form of FASD, is specifically identified in the 2020 Healthy People Maternal, Infant, and Child Health objectives to be addressed through funding of prevention and surveillance programs and the work of federally funded regional training centers $[1,6,7]$.

*Address correspondence to this author at the Department of Nutritional Sciences, Oklahoma State University, 312 Human Sciences, Stillwater, OK 74078, USA; Tel: 405-744-5965; Fax: 405-744-1357;

E-mail: shirley.evans@okstate.edu
Even though medical literature has reported that prenatal alcohol exposure is teratogenic, misconceptions about maternal alcohol consumption and the associated fetal effects are present in the practices of healthcare providers [8-10]. To promote prevention of prenatal alcohol exposure and interventions to mitigate alcohol's postnatal effects, the United States Centers for Disease Control and Prevention (CDC) provides continuing education to healthcare providers through their FASD Regional Training Centers (RTCs) [11]. Using a variety of interactive educational methods including role-playing, videotaped sessions, and case studies, members of the Midwest and Southeast RTCs used a competency-based curriculum to train healthcare providers in the identification of women 'at risk' for having an alcohol-exposed pregnancy and of children suspected as having FASD.

\section{PURPOSE}

Evaluating the practice behavior of healthcare providers is a critical step in determining competency integration after training [12]. This report describes results from an online survey developed to evaluate the incorporation of FASD competencies into the knowledge and practice behaviors of healthcare 
providers trained by Midwest and Southeast RTCs between 2002 and 2009, along with determining their perceived barriers in management of women identified for at-risk drinking or in the ability to make an FASD diagnosis in children.

\section{METHODS}

\section{Survey Design}

The healthcare providers were trained in the following core competencies developed in 2002 by the FASD RTCs, CDC, and the National Organization on Fetal Alcohol Syndrome: 1) Foundation, 2) Screening and Brief Interventions, 3) Models of Addiction, 4) Biological Effects of Alcohol on Fetus, 5) Screening, Diagnosis, and Assessment of FAS, 6) Treatment Across the Life Span for Persons with Fetal Alcohol Spectrum Disorders, and 7) Ethical, Legal, and Policy Issues [13]. When teaching the competency on screening, diagnosis, and assessment of FAS, the CDC promoted use of the following six Institute of Medicine (IOM) diagnostic categories for FASD: Fetal alcohol syndrome (FAS) with confirmed maternal alcohol exposure, fetal alcohol syndrome (FAS) without confirmed maternal alcohol exposure, partial fetal alcohol syndrome (PFAS) with maternal alcohol exposure, partial fetal alcohol syndrome (PFAS) without maternal alcohol exposure, alcohol related birth defects (ARBD), and alcohol related neurodevelopmental disorders (ARND) [3, 14]. For this study, the survey excluded questions regarding the competency on ethical, legal, and policy issues since the purpose was to evaluate FASD knowledge, practice behaviors, and barriers.
The online survey, specifically designed for this study, consisted of 35 multiple-choice and Likert (1 - 5) questions (7 demographic, 6 core competency, 18 knowledge and practice behavior, and 11 perceived barrier questions) and three hypothetical scenarios with photographs. The questions in the survey were developed by a team from the Midwest RTC after consultation with a health educator [12] and a review of prior surveys that used questionnaires to assess the knowledge, skills, and attitudes of healthcare providers $[8-10,15,16]$. Questions from two of the prior surveys reviewed by the team have demonstrated validity and reliability $[15,16]$. In this study, the scenarios (see Providers who treated women: SCENARIO 1, Providers who treated children: SCENARIO 2, and Providers who treated children: SCENARIO 3) simulated patient/client medical histories that healthcare providers might encounter when caring for women or children. Participants were not required to answer all survey questions. Forced choice questions, using an appropriate skip pattern, were embedded at points in the survey in an effort to provide definitive answers to categorize the participant's type of practice, knowledge, and practice behavior.

The self-report survey sectioned healthcare providers into categories with either questions for providers who treated women (9 knowledge and practice behavior and 3 perceived barrier questions) or for providers who treated children ( 9 knowledge and practice behavior and 8 perceived barrier questions), allowing for evaluation in the context of practice. As a pilot test for survey questions and procedures prior to administration of the study, the Southeast RTC conducted a focus group of five family physicians, six family medicine residents, one BA level project

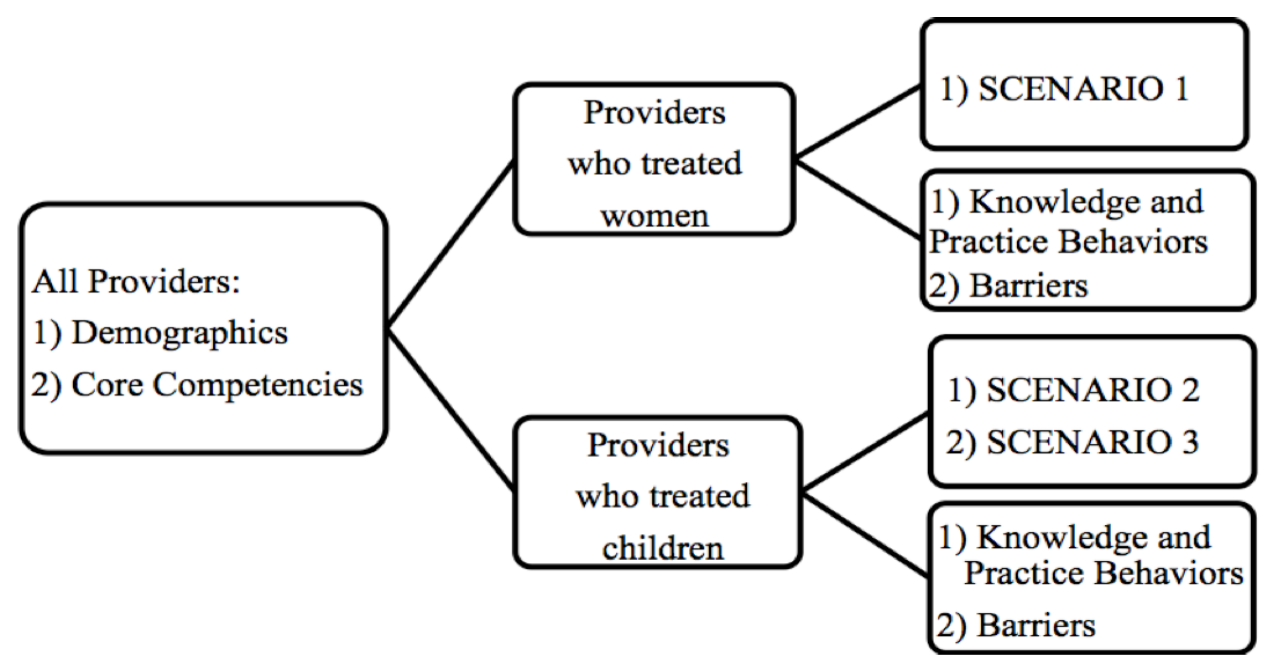

Figure 1: Survey Design. 
coordinator, and one master level public health student at Meharry Medical College's Department of Family and Community Medicine in Nashville, TN. The Saint Louis University Institutional Review Board (\#16349) approved the study, as the second author who is the PI of the Midwest RTC program was a former faculty member of Saint Louis University. The survey was made available online from February 2010 to July 2010. See Figure 1 for survey design.

\section{Participants}

Medical and allied healthcare providers, who treated women or children, and had attended one or more training sessions at the Midwest or Southeast RTC from 2002 to 2009, were invited to participate in the study. The total sample was 83 participants who provided demographic information; however, one person was unable to complete the survey. For the remaining set of results at study completion, there were 82 participants (37 providers who treated women, 45 providers who treated children), which represented a $7.5 \%$ response rate from 1,180 RTC-trained healthcare providers contacted. Participants responding to the survey resided in the states of Missouri, Arkansas, and Oklahoma covered by the Midwest RTC and Alabama, Florida, Georgia, Kentucky, Louisiana, Mississippi, South Carolina, and Tennessee covered by the Southeast RTC. Table 1 provides the demographics of the participants.

\section{Recruitment}

Using email addresses obtained from regional training center attendance lists, an electronically mailed cover letter contacted trained healthcare providers requesting their participation to evaluate the scope of FASD education and skill levels in various professional practices, when assessing women for prenatal alcohol exposure and children with FASD. Instructions given on the letter explained the survey would take no more than 15 minutes to answer and there was no obligation to complete it. A password and online link provided anonymous survey access, along with a separate link whereby the respondent could enter their name and contact information for a prize drawing upon completion of the survey. Additional e-mails were sent to the list of providers on a monthly basis for six months to remind contacts about the survey.

\section{Statistical Analysis}

Survey responses were stored on a secure online database without identifiers until completion of the study, whereby, the data manager in the Department of Family and Community Medicine at Saint Louis University downloaded responses for analysis. Descriptive statistics were conducted on survey responses including percentages, means, and standard deviations, using Predictive Analytics SoftWare (IBM, Armonk, New York). There was exclusion of missing responses from the data analysis of particular questions.

\section{RESULTS}

\section{Demographics for all Healthcare Providers}

Demographics in Table 1 show respondent ages ranged from 23 to 72 years with a mean age of 47.5

Table 1: Survey Demographics for All Healthcare Providers $(\mathbf{N}=\mathbf{8 2})$

\begin{tabular}{|c|c|}
\hline Demographics & n (\%) \\
\hline \multicolumn{2}{|l|}{ Gender $(n=82)$} \\
\hline Female & $65(79.3)$ \\
\hline Male & $17(20.7)$ \\
\hline Mean Age in Years (SD) & $47.5(9.3)$ \\
\hline \multicolumn{2}{|l|}{ Modes of Practice } \\
\hline Solo Practice (yes) & $11(12.6)$ \\
\hline Group Practice (yes) & $22(25.3)$ \\
\hline Faculty (yes) & $36(41.4)$ \\
\hline Other (yes) & $27(31.0)$ \\
\hline \multicolumn{2}{|l|}{ Healthcare Profession } \\
\hline Family Medicine & $8(9.2)$ \\
\hline Pediatrician & $4(4.6)$ \\
\hline OBGYN & $3(3.4)$ \\
\hline Psychiatry/Psychology & $9(10.3)$ \\
\hline Nursing (NP or RN) & $10(11.5)$ \\
\hline PT/OT/SLP/PA & $26(29.9)$ \\
\hline Other & $27(31.0)$ \\
\hline \multicolumn{2}{|l|}{ Practice $(n=78)$} \\
\hline High risk for FASD & $41(52.6)$ \\
\hline Low risk for FASD & $37(47.4)$ \\
\hline Practice Location & $(\mathrm{n}=79)$ \\
\hline Rural & $9(11.4)$ \\
\hline Suburban & $17(21.5)$ \\
\hline Urban (inner city) & $19(24.1)$ \\
\hline Urban (NOT inner city) & $18(22.8)$ \\
\hline Other & $16(20.3)$ \\
\hline \multicolumn{2}{|l|}{ Years in Practice $(n=80)$} \\
\hline Mean Years in Practice (SD) & $18.8(9.3)$ \\
\hline
\end{tabular}

$\mathrm{NP}=$ Nurse Practitioner. RN $=$ Registered Nurse. $\mathrm{PT}=$ Physical Therapist OT $=$ Occupational Therapist. SLP $=$ Speech Language Pathologist. $\mathrm{PA}=$ Physician Assistant 
years. Overall, more than $79 \%$ of respondents were female. Various disciplines of medical and allied health professionals participated in the survey with over half of practices having patients/clients at high risk for FASD (53\%). The respondents reported a mean of nearly 19 years in their respective practices.

\section{Core Competencies for all Healthcare Providers}

The core competencies evaluated in the survey represent the knowledge, skills, and attitudes that are necessary for all healthcare providers to prevent and treat FASD [13]. In examination of the competencies, over $90 \%$ of all respondents perceived they were proficient in educating pregnant women about the risks of alcohol-exposed pregnancies. However, $48 \%$ of respondents acknowledged the inability to conduct alcohol cessation or reduction brief interventions in women. In the core competencies related to FASD, the majority of healthcare providers indicated being able to perform the following: Recognize characteristic features of FAS/FASD (93\%), identify risk factors and interventions for secondary FASD disabilities (88\%), and initiate referrals for further workup (84\%). Yet, $42 \%$ were not confident in the selection of valid and reliable assessment instruments to screen for and diagnose FASD and other alcohol-related disorders in children. Frequencies of core competencies are available in Table 2.

\section{Learning Goals and Objectives}

The continuing education received by the healthcare providers was based on an outcome-based model with competencies defined by learning goals and objectives [13]. The objectives corresponded to a competency and consisted of specific steps leading to a particular learning goal for the healthcare provider. Following the core competency questions, the survey presented participants with a clinical scenario based on their practice area, whether treating women or children, designed to reflect integration of the learning goals and objectives per competency into clinical practice.

\section{Responses from Providers who Treated Women}

\section{Knowledge and Practice Behaviors}

When evaluating the knowledge and practice behaviors of providers who treated women, over $90 \%$ correctly reported screening the young pregnant female in SCENARIO 1 for alcohol intake, and 65\% used screening tools in their practice. Of the providers answering 'yes' to using a tool, $75 \%$ reported using the CAGE screening tool (cut down, annoyed, guilty, and eye opener) [17]. In addition, $75 \%$ of providers who treated women disclosed they were screening all women of childbearing age for at-risk drinking in their practices.

The majority of the providers who treated women $(86 \%)$ identify women 'at risk' for alcohol abuse and, equally important, $63 \%$ providers reported identifying women in their practices with heavy maternal drinking. However, $44 \%$ of the providers who identified women 'at risk' did not provide management themselves for women at high-risk of alcohol abuse. When asked about how the provider would care for the women 'at risk', nearly all of the providers (90\%) indicated they would refer their patients to substance abuse or mental health services as opposed to conducting a brief intervention with the women.

Many providers who treated women (61\%) had FASD resource materials available to educate women and $54 \%$ were aware of underlying risk factors in women with heavy drinking. Almost one-half of these providers practiced in communities relatively tolerant to heavy drinking (44\%), which suggests an acceptance

Table 2: Perceived Competencies after FASD Continuing Education for All Healthcare Providers ( $\mathrm{N}=83$ )

\begin{tabular}{|c|c|c|c|}
\hline & Yes & No & Uncertain \\
\hline Core Competency & n (\%) & n (\%) & n (\%) \\
\hline The ability to educate pregnant women about the effects of alcohol on their babies. & $77(92.8)$ & $2(2.4)$ & $4(4.8)$ \\
\hline The ability to conduct alcohol cessation or reduction brief interventions. & $42(51.2)$ & $24(29.3)$ & $16(19.5)$ \\
\hline $\begin{array}{l}\text { The ability to recognize the constellation of features associated with FAS and other } \\
\text { alcohol-related effects. }\end{array}$ & $72(92.8)$ & $1(1.2)$ & $5(6.0)$ \\
\hline $\begin{array}{l}\text { The ability to select valid and reliable assessment instruments to screen for/diagnose } \\
\text { FASD and other alcohol-related disorders. }\end{array}$ & $48(57.8)$ & $19(22.9)$ & $16(19.3)$ \\
\hline The ability to identify risk factors and interventions for secondary FASD disabilities. & $73(88.0)$ & $3(3.6)$ & $7(8.4)$ \\
\hline When appropriate, be able to make a referral for further workup in a child with a FASD. & $70(84.3)$ & $5(6.0)$ & $8(9.6)$ \\
\hline
\end{tabular}




\section{Scenarios in Survey for Healthcare Providers (photographs not included):}

\section{Providers who treated women: Scenario $1^{*}$}

SCENARIO 1. Miss Dunn, a single young female, is pregnant with her first child. She and her mother are in your clinic for the first prenatal visit. After reviewing her history, you note that she did not graduate from high school but is planning to get her GED. Would you screen her in reference to her alcohol intake?

*Corresponds with Table 3 Question 1.

Table 3: Knowledge and Practice Behaviors in Providers who Treated Women $(\mathrm{N}=37)$

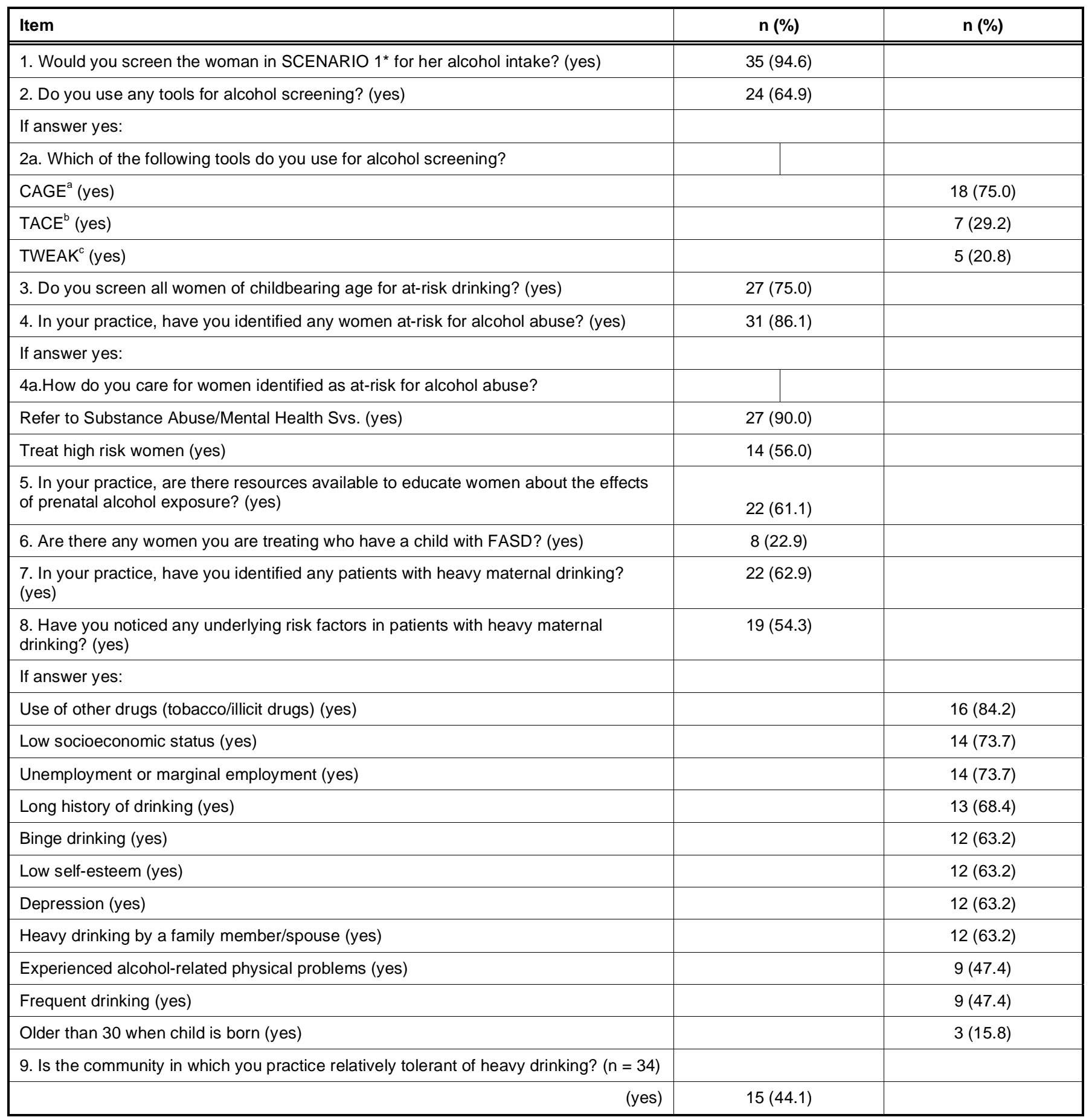

*Providers who treated women: SCENARIO 1. ${ }^{\mathrm{a}} \mathrm{CAGE}=$ cut down, annoyed, guilty, and eye opener [18]. ${ }^{\mathrm{b}} \mathrm{TACE}=$ tolerance, annoyed, cut down, and eye opener [25]. ${ }^{\circ}$ TWEAK = tolerance, worry, eye opener, amnesia, and cut down [26]. 
of drinking at social events and is a risk factor for FASD [18]. Unfortunately, 23\% cared for women who already had a child with FASD. Results regarding knowledge and practice behaviors for providers who treated women are found in Table $\mathbf{3}$.

\section{Barriers}

Providers who treated women in their practices reported several barriers encountered in relation to screening, treating, and referring women of childbearing age for at-risk drinking. In screening women for atrisk drinking, for $38 \%$ of the providers, there were no barriers. However, $19 \%$ believed women may perceive them as being insensitive and $16 \%$ felt lack of time and training as issues when screening women in regards to their alcohol consumption. To administer an intervention themselves for at-risk drinking in women of childbearing age, the barriers included the following: Lack of training $(30 \%)$, limited time $(27 \%)$, and no financial reimbursement (24\%). The perception of being insensitive (22\%) and no financial reimbursement $(16 \%)$ were also barriers for providers in referring women of childbearing age for at-risk drinking. Barriers for providers caring for women are in Table 4.

\section{Responses from Providers who Treated Children}

\section{Knowledge and Practice Behaviors}

Over $90 \%$ of providers who treated children recognized, from the facial characteristics (seen in the photograph) and the historical information given, that the infant in SCENARIO 2 needed further evaluation for possible FAS. From the group that recognized the need for screening, $71 \%$ identified the three major diagnostic FAS components (facial anomalies, growth deficits, and central nervous system abnormality), but less than one-half $(49 \%)$ chose all three CDC diagnostic facial dysmorphologies (smooth philtrum, thin vermillion, and small palpebral fissures) correctly. The instruments the healthcare providers used most commonly in screening were: Growth charts (70\%), lip philtrum guide (58\%), tape measure $(58 \%)$, palpebral fissure length chart $(50 \%)$, and reflex hammer (41\%).

All providers who treated children (100\%) responded in SCENARIO 3 that a history of prenatal substance abuse should be determined when eliciting the child's medical history. All respondents also correctly identified the need to refer this child for further

Table 4: Barriers Encountered by Providers in Care of Women for At-Risk Drinking ( $\mathrm{N}=37$ )

\begin{tabular}{|c|c|}
\hline Item & n (\%) \\
\hline \multicolumn{2}{|c|}{ 1. Screening women of child-bearing age for at-risk drinking. } \\
\hline No barriers & $14(37.8)$ \\
\hline Might be perceived as insensitive & $7(18.9)$ \\
\hline Lack of time & $6(16.2)$ \\
\hline Lack of training & $6(16.2)$ \\
\hline Confidentiality issues & $5(13.5)$ \\
\hline No financial reimbursement & $3(8.1)$ \\
\hline \multicolumn{2}{|c|}{ 2. Treating women of childbearing age for at-risk drinking. } \\
\hline Lack of training & $11(29.7)$ \\
\hline Lack of time & $10(27.0)$ \\
\hline No financial reimbursement & $9(24.3)$ \\
\hline Confidentiality issues & $5(13.5)$ \\
\hline No barriers & $5(13.5)$ \\
\hline Might be perceived as insensitive & $3(8.1)$ \\
\hline \multicolumn{2}{|c|}{ 3. Referring women of child-bearing age for at-risk drinking. } \\
\hline No barriers & $16(43.2)$ \\
\hline Might be perceived as insensitive & $8(21.6)$ \\
\hline No financial reimbursement & $6(16.2)$ \\
\hline Lack of training & $5(13.5)$ \\
\hline Confidentiality issues & $1(2.7)$ \\
\hline
\end{tabular}




\section{Providers who treated children: Scenario $2^{\star}$}

SCENARIO 2. Mary, a young, single Native American mother, brings her infant to your practice for a well-baby visit. This is her first child and she has little family support. History reveals the infant has been somewhat irritable and listless, with feeding difficulties due to a poor suck. Would you further evaluate this infant for a possible diagnosis of FAS?

${ }^{*}$ Corresponds with Table 5 Question 1.

\section{Providers who treated children: Scenario $3^{*}$}

SCENARIO 3. Bobby, an 8 year old Caucasian male, is brought to your clinic by his parents for an evaluation secondary to his developmental delays and various behavioral/neurological deficiencies. During your examination, you note, along with his learning disabilities and attention deficit problems, the following characteristics: growth deficiencies, vision and hearing problems, craniofacial abnormalities, and mood swings. During the course of this visit, what information would you elicit about the child's history regarding prenatal exposure to which, if any, of the following?

*Corresponds with Table 5 Question 6.

Table 5: Knowledge and Practice Behaviors of Providers who Treated Children $(\mathbf{N}=45)$

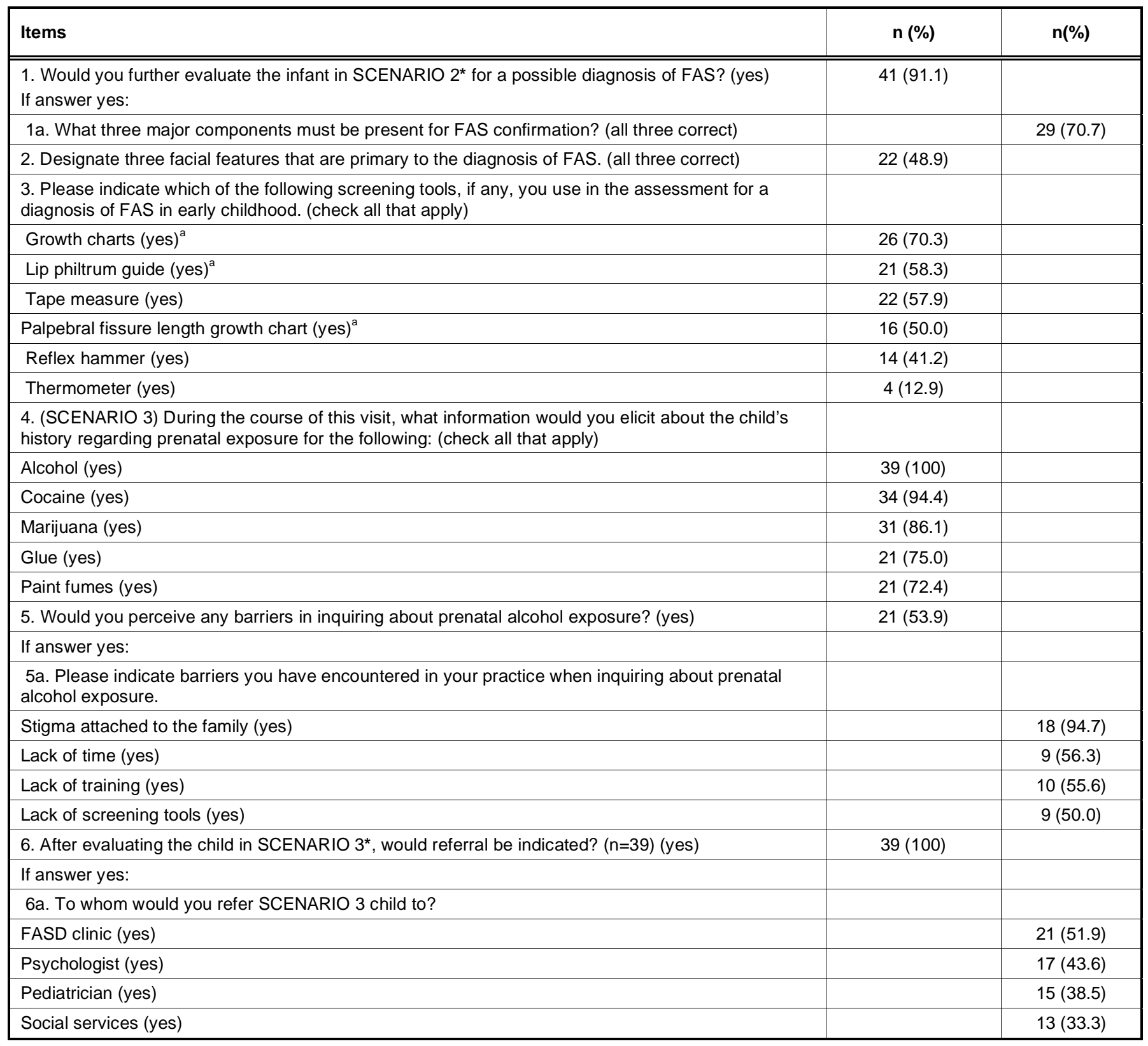


(Table 5). Continued.

\begin{tabular}{|c|c|c|}
\hline Items & n (\%) & $n(\%)$ \\
\hline Psychiatrist (yes) & & $12(30.8)$ \\
\hline Therapist (yes) & & $10(25.6)$ \\
\hline Geneticist (yes) & & $10(25.6)$ \\
\hline Dysmorphologist (yes) & & $8(20.5)$ \\
\hline 7. Do you have any patients with FAS or FASD under your care at this time? (yes) & & $14(35.9)$ \\
\hline \multicolumn{3}{|l|}{ If answer yes: } \\
\hline 7a. I have pediatric patients with FAS (yes) & & $9(75.0)$ \\
\hline 7b. I have pediatric patients with FASD (yes) & & $10(76.9)$ \\
\hline \multicolumn{3}{|c|}{ 7c. What are the most common deficits in your pediatric patients with FASD or FAS? (all that apply) } \\
\hline Impulsivity (yes) & & $12(85.7)$ \\
\hline Social and emotional intelligence (yes) & & $11(78.6)$ \\
\hline Facial dysmorphology (yes) & & $11(78.6)$ \\
\hline Cognition (yes) & & $10(71.4)$ \\
\hline Language sequencing (yes) & & $8(57.1)$ \\
\hline Fine and gross motor skills (yes) & & $8(57.1)$ \\
\hline Arousal and attention (yes) & & $7(50.0)$ \\
\hline Auditory processing (yes) & & $6(42.9)$ \\
\hline Receptive speech (yes) & & $5(35.7)$ \\
\hline Growth retardation (yes) & & $0(0.0)$ \\
\hline \multicolumn{3}{|l|}{$\begin{array}{l}\text { 8. Do you use any diagnostic schema for FASD in your practice? } \\
(n=39)\end{array}$} \\
\hline (yes) & $9(23.1)$ & \\
\hline \multicolumn{3}{|l|}{ If answer yes: } \\
\hline \multicolumn{3}{|l|}{ 8a. Which of the following do you use? } \\
\hline Seattle 4-digit code $(n=7)$ (yes) & & $3(75.0)$ \\
\hline American Academy of Pediatrics $(n=5)$ (yes) & & $5(71.4)$ \\
\hline Institute of Medicine $(n=4)(y e s)^{b}$ & & $3(60.0)$ \\
\hline \multicolumn{3}{|l|}{ 9. Have you diagnosed any patients with secondary FASD disabilities? $(n=39)$} \\
\hline (yes) & $13(33.3)$ & \\
\hline \multicolumn{3}{|l|}{ If answer yes: } \\
\hline \multicolumn{3}{|l|}{ 9a. Symptoms used in making secondary FASD disability diagnosis. (all that apply) } \\
\hline Mental health problems (yes) & & $13(100)$ \\
\hline Disrupted school experiences (yes) & & $11(84.6)$ \\
\hline Trouble with law enforcement (yes) & & $4(30.8)$ \\
\hline Sexual misconduct (yes) & & $3(23.1)$ \\
\hline
\end{tabular}

andicates correct answer. 'Indicates RTCs' diagnostic schema of choice. *Providers who treated children: SCENARIO 2 . 'Providers who treated children: SCENARIO 3

follow-up with $52 \%$ referring to an FASD clinic. When asked about their own patients/clients who were diagnosed with FASD, greater than $70 \%$ of providers had encountered impulsivity, facial dysmorphologies, social/emotional intelligence deficits, and cognitive abnormalities. Other identified deficits included language sequencing (57\%), fine and gross motor skills (57\%), and arousal and attention problems (50\%). Symptoms of secondary FASD disability used in diagnosis by the providers were mental health problems (100\%), disrupted school experiences (85\%), trouble with law enforcement $(31 \%)$, and sexual misconduct (23\%). Yet, only $23 \%$ of respondents reported using FASD diagnostic schema in their practice with $75 \%$ of them choosing the Seattle 4-Digit Diagnostic Code and 60\% employing the RTC preference, the Institute of Medicine (IOM) diagnostic categories $[14,19]$. Results on knowledge and practice behaviors for providers who treated children are in Table 5. 
Table 6: Practice Barriers that may Limit the Ability to Make a FASD Diagnosis in Providers who Treated Children $(\mathrm{N}=45)$

\begin{tabular}{|c|c|c|c|}
\hline & $1=$ Not at all a barrier & Neutral & $5=$ Very much a barrier \\
\hline Barrier & $\mathrm{n}(\%)$ & $\mathrm{n}(\%)$ & $\mathrm{n}(\%)$ \\
\hline 1. It is beyond the scope of my practice. & $18(48.6)$ & $4(10.8)$ & $15(40.5)$ \\
\hline 2. Lack of time needed to make diagnosis. & $13(38.2)$ & $12(35.3)$ & $9(26.5)$ \\
\hline 3. Lack of specific training to make a diagnosis. & $14(41.2)$ & $4(11.8)$ & $16(47.1)$ \\
\hline $\begin{array}{l}\text { 4. Diagnosis is unlikely to improve treatment } \\
\text { outcome. }\end{array}$ & $22(61.1)$ & $6(16.7)$ & $8(22.2)$ \\
\hline 5. Diagnosis will stigmatize patient and/or family. & $15(44.1)$ & $9(26.5)$ & $10(29.4)$ \\
\hline $\begin{array}{l}\text { 6. Better qualified specialists are available to make } \\
\text { the diagnosis. }\end{array}$ & $13(37.1)$ & $8(22.9)$ & $14(40.0)$ \\
\hline 7. Lack of awareness of problems with FASD. & $22(64.7)$ & $6(17.7)$ & $6(17.6)$ \\
\hline $\begin{array}{l}\text { 8. Personal discomfort in addressing a FASD } \\
\text { diagnosis. }\end{array}$ & $23(67.6)$ & $7(20.6)$ & $4(11.8)$ \\
\hline
\end{tabular}

\section{Barriers}

Providers who treated children identified several practice barriers, which limited their ability to confirm an FASD diagnosis. These barriers included: The stigma that would be attached to the family (29\%), a lack of specific training to make a diagnosis (47\%), and an FASD diagnosis is beyond the scope of their practice $(41 \%)$, which may be associated with the percentage of therapists or other healthcare providers whose jobs do not include diagnostic responsibilities. Many of the providers (40\%) also felt there were specialists better qualified to make the diagnosis, along with $27 \%$ indicating lack of time as an issue. A listing of practice barriers for providers who treated children are in Table 6.

\section{DISCUSSION}

The effects of alcohol on fetal development are multi-focal, incurable, and completely preventable by abstinence from alcohol during pregnancy [20, 21]. Healthcare providers play a vital role in delivering FASD-related information to women at high risk for drinking and in caring for children with FASD $[8,10,15$, 22]. To enhance knowledge and practice behaviors, the Midwest and Southeast Regional Training Centers instructed healthcare providers in screening and interventions of women for at-risk of drinking, along with the diagnosis of and interventions for children with FASD. This study evaluated the practice behaviors in trained providers who treated women or children, based on FASD competencies approved by the CDC.

In providers who treated women, there was strong agreement in screening women for alcohol intake, especially when pregnant or during the childbearing years. Nonetheless, the tool used most often was the CAGE, in contrast to RTC recommendations of the TACE (tolerance, annoyed, cut down, and eye opener) or the TWEAK (tolerance, worry, eye opener, amnesia, and cut down) as a screening tool [23-25]. The findings also suggest there are significant numbers of women consuming alcohol during pregnancy since over half of providers identified patients/clients in their practices at high risk for having a child with FASD. In respect to follow-up, although the majority of the respondents may be reluctant to conduct brief interventions for at risk drinking, they were willing to refer women to treatment centers.

Concurrently, the findings in this study indicate that a majority of the responding providers who treated children had competency in identifying the characteristic features in children with FAS. A majority were also cognizant of secondary FASD risk factors, such as mental health problems, disrupted school experiences, and trouble with law enforcement. However, many did not utilize FASD diagnostic schema, most notably in reference to criteria set by the Institute of Medicine.

Although the time between the providers' training and data collection varied in this study, our results are consistent with findings from other FASD studies developed in a comparable manner to explore the knowledge and practice behaviors in healthcare providers $[10,15]$. There have been similar reports regarding barriers of limited time and patient-perceived insensitivity experienced by obstetrician-gynecologists, along with using the CAGE instead of the T-ACE 
screening questionnaire [15]. It also was found that many pediatricians did not diagnose FAS with the IOM criteria and had concerns with a lack of training and use of valid screening instruments [10].

Overall, results in this study suggest the respondents perceive competency in identifying and providing a referral for women or in recognition of a child with FAS but may lack competency in providing interventions for women 'at risk' for drinking during pregnancy or in use of the FAS screening tools recommended by the FASD Competency-Based Curriculum Development Guide [13].

\section{LIMITATIONS}

Clearly, a low response rate is a limitation to this assessment, which may be secondary to an individual's preference for a hard copy instead of electronic version. Since the survey was self-reported, the participants may have responded to some questions with socially desirable answers. However, the survey was anonymous without personal identifiers. In our study, healthcare providers were generally from the midwestern and southeastern states and may not be representative of all providers across the United States. Additional limitations may include the length, order, wording, and inaccurate completions of survey questions. There also may have been variability between regional training center instructors, length of time between training and assessment, or time allotment for teaching specific competencies.

\section{TRANSLATION TO HEALTH EDUCATION PRACTICE}

Through the Midwest and Southeast RTC continuing education programs, providers who treat women or children attained high levels of FASD competency. Nevertheless, survey results indicate ongoing continuing education is critical to maintain effective healthcare provider competency in screening women at-risk for alcohol-exposed pregnancies and identifying children with FASD. Future RCT continuing education for healthcare providers should emphasize enhancing practice behaviors in the intervention of women at-risk for alcohol-exposed pregnancies, promoting the use of recommended FASD diagnostic schema and screening tools for children, and addressing such barriers as the perceived insensitivity when screening or referring individuals or the fear of attaching stigma to a family with an FASD diagnosis. Through these measures, the practice behaviors in healthcare providers will seek to increase prevention of prenatal alcohol exposure and intervention to reduce the postnatal FASD effects in their patients [26].

In summary, the results of this study suggest a need for continuing education to focus on methodologies that assist providers who treat women or children to incorporate effective FASD prevention, screening, diagnostic, and treatment procedures easily into their daily practice.

\section{REFERENCES}

[1] Jones KL, Smith DW, Ulleland CN, Streissguth P. Pattern of malformation in offspring of chronic alcoholic mothers. Lancet 1973; 301: 1267-71. http://dx.doi.org/10.1016/S0140-6736(73)91291-9

[2] Warren K, Floyd LL, Calhoun F, et al. Consensus statement on FASD. Washington, DC: National Organization on Fetal Alcohol Syndrome 2004

[3] Bertrand J, Floyd RL, Weber MK, et al. Fetal alcohol syndrome: guidelines for referral and diagnosis. Atlanta: Centers for Disease Control and Prevention 2004.

[4] Brown NN, Rich SD. A neurodevelopmental paradigm for fetal alcohol spectrum 'disorder. The Judges' Page [serial on the Internet]. 2014 May 19; [cited 2014 June 26]: [about 3 screens]. Available from: http://www.casaforchildren.org/site/ c.mtJSJ7MPIsE/b.8968413/k.9568/JP3_Rich_Brown.htm

[5] American Psychiatric Association. Diagnostic and statistical manual of mental disorders, fifth edition. Arlington: American Psychiatric Publishing 2013.

[6] Kodituwakku P. Defining the behavioral phenotype in children with fetal alcohol spectrum disorders: a review. Neurosci Biobehav Rev 2007; 31: 192-201. http://dx.doi.org/10.1016/j.neubiorev.2006.06.020

[7] Services USDoHaH. Healthy People 2020: Maternal, infant and child health. In: Promotion OoDPaH, editor. Washington, DC. 2010. http://www.healthypeople.gov/2020/topicso bjectives2020/objectiveslist. aspx?topicld $=26$

[8] Brimacombe $M$, Nayeem A, Adubato S, Dejoseph $M$, Zimmerman-Bier B. Fetal alcohol syndrome related knowledge assessment and comparison in New Jersey health professional groups. Can J Clin Pharmacol 2008; 15: e57-65.

[9] Wedding D, Kohout J, Mengel MB, et al. Psychologists' knowledge and attitudes about fetal alcohol syndrome, fetal alcohol spectrum disorders, and alcohol use during pregnancy. Prof Psychol Res Pr 2007; 38: 208-13. http://dx.doi.org/10.1037/0735-7028.38.2.208

[10] Gahagan S, Sharpe TT, Brimacombe M, et al. Pediatricians knowledge, training, and experience in the care of children with fetal alcohol syndrome. Pediatrics [serial on the Internet]. 2006 September 1; [cited on 2014 June 26]; 118: e657-68. http://dx.doi.org/10.1542/peds.2005-0516

[11] Alexander M, Dang E, Floyd LR, et al. Educating health professionals about fetal alcohol spectrum disorders. Am $J$ Health Educ 2007; 38: 364-73.

http://dx.doi.org/10.1080/19325037.2007.10598996

[12] Fox RD. Revisiting "discrepancy analysis in continuing medical education: a conceptual model" 1983. J Contin Educ Health Prof $2011 ; 31: 71-6$. http://dx.doi.org/10.1002/chp.20104

[13] Services USDoHaH, Prevention CfDCa, Disabilities NCoBDaD, Centers FRT, Syndrome NOoFA. Fetal alcoho 
spectrum disorders; competency-based curriculum development guide for medical and allied health education and practice. Atlanta 2009

[14] Hoyme HE, May PA, Kalberg WO, et al. A practical clinical approach to diagnosis of fetal alcohol spectrum disorders: clarification of the 1996 Institute of Medicine criteria. Pediatrics 2005; 115: 39-47. http://www.ncbi.nlm.nih.gov/ pmc/articles/PMC1380311/

[15] Diekman ST, Floyd RL, Decoufle P, Schulkin J, Ebrahim SH, Sokol RJ. A survey of obstetrician-gynecologists on their patients' alcohol use during pregnancy. Obstet Gynecol 2000; 95: 756-63. http://dx.doi.org/10.1016/S0029-7844(99)00616-X

[16] Clarke M, Tough S, Cook J. Knowledge and attitudes of health professionals about fetal alcohol syndrome: Results of a national survey [online]. Public Health Agency of Canada 2005; 1-64.

[17] Ewing JA. Detecting alcoholism. The CAGE questionnaire. JAMA 1984; 252: 1905-7. http://dx.doi.org/10.1001/jama.1984.03350140051025

[18] May PA. A multiple-level, comprehensive approach to the prevention of fetal alcohol syndrome (FAS) and other alcohol-related birth defects (ARBD). Int J Addict 1995; 30: 1549-602.

[19] Astley SJ, Clarren SK. Diagnosing the full spectrum of fetal alcohol-exposed individuals: introducing the 4-digit diagnostic code. Alcohol Alcoholism 2000; 35: 400-10. http://dx.doi.org/10.1093/alcalc/35.4.400
[20] Stratton K, Howe C, Battaglia F. Fetal alcohol syndrome: diagnosis, epidemiology, prevention, and treatment: National Academy Press 1996.

[21] Daily $\mathrm{DK}$, Ardinger $\mathrm{HH}$, Holmes GE. Identification and evaluation of mental retardation. Am Fam Physician 2000 61: 1059-67, 70 .

[22] Sick S, Dempster, JS. Fetal alcohol syndrome: the nurse practitioner perspective. J Am Acad Nurse Pract 1996; 8: 343-9.

http://dx.doi.org/10.1111/j.1745-7599.1996.tb00673.x

[23] Alcoholism NloAAa. Screening for alcohol use and alcoholrelated problems. In: Services USDoHH, editor. Rockville: NIAAA Publications Distribution Center 2005; pp. 1-8.

[24] Sokol RJ, Martier SS, Ager JW. The T-ACE questions practical prenatal detection of risk-drinking. Am J Obstet Gynecol 1989; 160: 863-70. http://dx.doi.org/10.1016/0002-9378(89)90302-5

[25] Chan AWK, Pristach EA, Welte JW, Russell M. Use of the TWEAK test in screening for alcoholism heavy drinking in 3 populations. Alcohol Clin Exp Res 1993; 17: 1188-92. http://dx.doi.org/10.1111/j.1530-0277.1993.tb05226.x

[26] Streissguth AP, Bookstein FL, Barr HM, Sampson PD, O'Malley K, Young JK. Risk factors for adverse life outcomes in fetal alcohol syndrome and fetal alcohol effects. JDBP 2004; 25: 228-38. http://www.ncbi.nlm.nih.gov/pubmed/ 15308923 